Unity Journal

Vol. III, 317-330, 2022

Doi:https://doi.org/10.3126/unityj.v3i01.43335

Prithvi Narayan Shah Research Center

Directorate General of Military Training, Nepali Army

Kathmandu, Nepal

\title{
Social Media and its Impacts in Human Minds
}

\section{Sulav Adhikari}

\begin{abstract}
In today's world, social media can make differences in the minds of people across the world. It has not only become the source of information but also is a part of human's life. It can be termed as the vehicle of communication which lets each one of us to convey and share our content in each and every corner of the world via the internet. According to the data of the year 2020, there were more than 3.6 billion users of social media and it's expected to increase up to 4.41 billion till 2025 which is massive.
\end{abstract}

The above extracted data is huge, and it is crystal clear that social media is booming day by day. Indeed, among all the young generations are the active users of social media platforms. Knowing these data, we can observe the significance of social media in our life. The social media platforms that are utilized rapidly include Facebook, YouTube, WhatsApp, Instagram and so on. These platforms have a prominent impact on everyone's life whether it may be positive or negative.

On the positive side it permits us to communicate and connect with our dear ones. Also, we can gain up-to-date information and news happening around the globe. Many skills and opportunities can be flourished and gained respectively with the assistance of social media and its platforms. On the negative side, cyber bullying, fraud, rumour spreading etc. are gaining huge attention which is the drawback of social media. And mostly the youths are found being engaged in such activities. So, these social media platforms exhibit both the positive and negative sides.

In summary, we observed that, if social media and its platforms are used in a productive and informative technique, then we tend to secure multiple benefits from it. Otherwise, it will take no time to degrade our valuable time and lives. After glancing, observing and analyzing the above stated statements and problem domain, discussion and explanation must be performed on how these social media and its platforms will impact and influence young high school students before their minds fully develop.

Keywords: Social media, information, communication, internet, young generation, social media platforms.

\section{Introduction}

Social networking has become an everyday part of many peoples' lives as evidenced by the huge user communities. Around 4.55 billion people utilize social media globally. Approximately around $57.6 \%$ of 
the world's population utilizes social media (Smart Insights, 2021). According to the data gathered in January 2021, there were around 13 million users of social media in Nepal. According to the October 2021 survey, Facebook is ranked as the most popular social media platform worldwide on the basis of number of active users. Currently it holds more than 2.89 billion monthly active users (DataReportal, 2021).

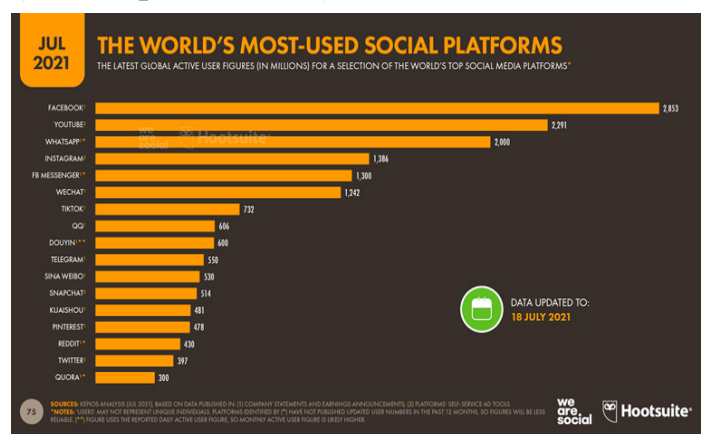

Figure 1: Most Used Social Media (DataReportal , 2021)

Considering the above paragraph mentioning facts and figures, we can clearly analyze the advancement and growing usability of social media. With the technological advances and the increased scope of media, communication with anyone around the world has become easy. Earlier we had to wait for days or sometimes months for a beautiful handwritten letter sent through post from close and loved ones. But now any dialogue happens in a fraction of seconds. Social media is one of the major platform communications. We cannot imagine our daily routine without it. Internet penetration has brought the world together on one platform. Now we can easily connect with anyone from a different city or for that matter, a different country. With the pictures or videos that are overflowing the social media platforms like Facebook and Twitter one is constantly updated about near and dear ones.
Along with considering above mentioned analysis, there is also another point to consider that, nothing comes with all good or best. As there is a saying, "Every coin has its two sides", and so does social media. While talking about the positive side of the coin, social media has been one of the best sources of communication, and advertising because of its ever-increasing scope and reach, cost effectiveness, business development features, worldwide connectivity, matchmaker or find one's romance, opportunities for job, free publicity, real time information sharing, platform to share cultural information, and much more.

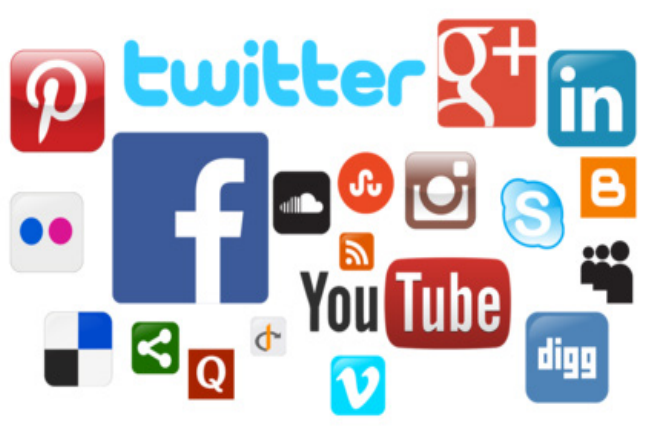

Figure 2: Social Media (Questex LLC, 2021)

More importantly one cannot neglect the fact that there is also a negative side to the coin. Social media keeps you hooked up for hours and your time is wasted. Hence, it can be called addictive. The other negative aspects would include the increase in crime (cybercrime), increasing fraud, hacking of information, virus attacks, low productivity in work, negative publicity and low internet penetration in some parts of the world. One cannot just overlook the unfavorable aspects of social media.

In conclusion, when a person learns to balance his time for social media keeping in mind the other activities in his daily routine 
and taking care of his security, social media can always be a boon (Investopedia, 2021). Moreover, how social media has an impact on humans and the society is clarified in this article.

\section{Background}

Social Media and its platforms like; Facebook, YouTube, Instagram, WhatsApp etc. are regarded as the most popular destinations on the web. It is not fair to say that the social media has only spread positivity, somehow in some cases it has also contributed to cybercrime, fraud, increase addiction level, bullying and other negative aspect on the web but the question is had they as a whole contributed to deliver positive or negative consequences in the lives of people and society?

Highlighting the fact that in today's world some believe that, it is evident that social media has a significant influence on our culture, business and entire worldview. Social media is a new arena where individuals can discuss ideas, interact with, relate to, and mobilize for a cause, receive counsel, and provide instruction. Social media has broken down communication barriers and provided decentralized communication channels, permitting everyone, including those in dictatorial nations, to have a voice and engage in a democratic manner. It enables common interest-based groups such as students, to collaborate on a project outside of class. Students benefit tremendously from social networking sites in school, particularly through communicating with one another on school assignments and collaborative group projects outside of class. For instance, Facebook permits students to meet outside of class to discuss ideas about their homework or tasks (Investopedia, 2021).
Similarly, at present, the significance of social media is also analyzed by the educational sectors. Like, schools are utilizing blogs effectively as teaching tools, which has the added benefit of boosting skills in English, written expression, and creativity abilities. Social media is a wonderful marketing promotional equipment as well because it has an exponential user growth, businesses utilize it for product marketing through advertising, where they showcase brands, debate features, and raise awareness. In reality, advertising is the primary method used by social media firms to earn capital and support and endure their functions. Furthermore, social networking sites are applicable to convey information more quickly than traditional news channels or any other type of media. It encourages innovation and cooperation with a diverse scope of contributors on a variety of affairs including education, business, politics, racism, health, relationships etc. In the context of Nepal, social media play the most vital role in spreading the news and compel the concerned authorities to deal with it. The news which the popular news magazines sources or authorities are unable to seek are accomplished by social media platforms. Through this we can also distinguish the importance of social media.

On the other hand, although social media has provided numerous advantages such as enabling us to communicate with peers and family instantly and conveniently all over the world, fragmenting down the international boundaries and cultural barriers. Social media is robbing us of trust and comfort we formerly placed in one another, substituting virtual connection for the human fellowship, physical and emotional support we once derived from one another. It robs us of our self-control and capability to think for 
ourselves, instead making us stupid enough to join any community that broadcasts deviant statements that tickle our ears and please our senses without weighing the repercussions.

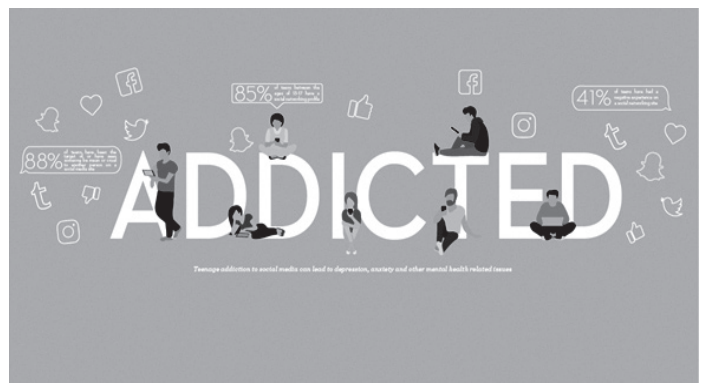

Figure 3: Impacts of Social Media (Utopia Educators, 2021)

Unfortunately, social media is causing us to become one of the most unfriendly and antisocial societies, but we still prefer texting to phone talks, online chat to face-to-face meetings, and many have abandoned human connection in favor of more convenient platforms like; Facebook, Instagram, Twitter and so on (Understanding Social Media, 2019).

\section{Statement of the Problem}

Along with the advancement and rapid growth in the utilization of social media, it is observed that to some extent the academic performance of students is facing a lot of neglect and obstacles, employment at the workplace has suffered a lot of neglect, relationships have been affected, and it has imported the opportunities for hackers. There is a divergence and fragmented focus between social networking activities and education, businesses and jobs at the workplace. It has also been found that students and employees invest more time on social networking sites than on their studies and professions respectively (Lifespan, 2020). As a result, the research question is around how consumers perceive social media and how they utilize it.

\section{Objectives}

The article has the following objectives. They are:

$\checkmark$ To learn about the different social networking sites that are often utilized in modern culture (society),

$\checkmark$ To discover the motivations behind people's participation in social networks and its utilization,

$\checkmark$ To govern the influence of social networks on the lives of individuals in the society, and

$\checkmark$ To identify how the usage of social media has affected the public positively and negatively.

\section{Research Questions}

Some of the research questions are listed out below:

a) How does social media impact human minds and society?

b) What are the reasons for joining social media?

c) Which is the most preferred social media platform?

d) Is social media a must in today's world?

\section{Scope}

The primary purpose of this research article work is to investigate and inspect the influence of social networks/media on people's lives and society. During the study and research, the inclusion of social media and its platforms such as Facebook, YouTube, Tik Tok, etc. are must. The study concentrates on social media, prominent social media sites and the effects that they deliver either positively or negatively. Such research articles assist in 
providing the needy knowledge and message regarding social media, its renowned sites, and the impact that they rise in the daily lives of human beings.

\section{Conceptual Clarification}

Let's clarify some of the topics or concepts relating to the subject.

\section{Internet}

The Internet is a global network of interconnected computer networks that utilize the standard Internet protocol suite (TCP/IP) to serve billions of users. It is composed of millions of private, public, academic, business, and government networks ranging in size from local to global in scope and associated by a diverse range of electronic, wireless and optical networking technologies. The Internet has a wide range of information resources and services, like the World Wide Web (WWW) interconnected hypertext contents and the infrastructure to facilitate email service. While the popularity of social networking continues to grow, new applications for the technology are being explored on a regular basis. For business communications, internet technologies provide several options, ranging from text-based e-mail to images and sound transmission, through their own websites. Organizational websites present difficulties and possibilities for public relations professionals by fostering communication with the organization's various audiences. Advertising was the only way to deliver a controlled mass communication prior to the creation of the WWW (Techopedia, 2021),

\section{Social Media}

Social media has evolved into one of the most popular means of engaging and connecting with others via gadgets like; mobile, computer etc. Though there are several platforms for social media, they all offer the same main goal of facilitating social connection. Social media has expanded into more than simply text-based interactions, but also images, videos, and a variety of other types of content. This has improved user's ability to communicate with others while also allowing them to express and share more broadly through computing engagement. Social media has exploded in popularity over the last several decades, producing plenty of well-known applications in the social networking field (Investopedia, 2021).

\section{Social Media Platforms}

List of some of the biggest social networks used today:

a) Facebook (http://www.facebook. com/) - Facebook is one of the most popular and reputed social networking sites on the web that makes it convenient to convey and share any connection, connect and communicate with the family, peers and relatives online. In 2004, Mark Zuckerberg introduced Facebook to the world and today it is no doubt that it's the largest social media platform globally with one billion plus consumers.

b) YouTube (http://www.youtube.com/) - YouTube is an open source and costless video content sharing website which makes it convenient in viewing videos on the internet. It also provides a platform to showcase your talent and creativity by creating and uploading your video content and sharing with others around the globe. It is also another popular site which was created in 2005. 
c) WhatsApp (https://www.whatsapp. com/) - WhatsApp is a social media application owned by Facebook. It permits its consumers to send text messages, voice clips and voice messages, make audio and video calls. Furthermore, the sharing of the pictures, videos, documents and many more are also possible via WhatsApp.

d) Instagram (https://www.instagram. com/) - Instagram is another social media platform that is owned by Facebook in 2012. With the assistance of this app, the consumers can edit and upload photos, videos, send messages, share the contents and moments, make friends, make voice messages, make audio and video calls. Instagram has also the feature to follow the friends and idols like; celebs, politicians etc. who use this application. There are other more features and functionality of this application.

e) Tik Tok (https://www.tiktok.com/) - It won't be any unfair to say that Tik Tok is one of the fastest growing social media platforms. The application motto is to promote art, creativity and talent of the users. It is a video sharing application that enables the users to upload short videos (i.e. 15 second) on any content. It has gained a huge audience and popularity in a short interval of time period.

\section{f) Snapchat (https://www.snapchat.} com/) - Like other social media, snapchat also allows the users to send messages, make audio and video calls, send videos, pictures and so on. But the uniqueness of this app is that any images, messages and videos you send to your receiver are made available only for a short time by default. Snapchat is utilized mostly by the youths and renowned personalities like celebrities to share their events and moments happening in their life

g) Pinterest (http://www.pinterest. com/) - Pinterest is a social networking site where you are allowed to gather and share pictures of anything that tickles your interest. A popular picture-sharing website that lets anybody effortlessly share photos, create collections, and do other things.

\section{LinkedIn (http://www.linkedin.com/) -} LinkedIn is a social media platform that focuses on career development through networks. Job and employment opportunities are also provided by the assistance of this application. This site is also valuable and effective for educational and professional purposes. It is also termed as the job and employee hunting platform. Furthermore, connections between friends and colleagues are also prevalent via LinkedIn (Investopedia, 2021).

\section{Social Networking}

The utilization of internet-based social media platforms to keep connected with peers, colleagues, relatives, family, employees, customers, clients, consumers is referred to as social networking. Social networking services such as LinkedIn, Facebook, Instagram, Twitter etc. can serve either a social or a business function, or both. It is the technique of increasing the number of one's commercial and social contacts through connecting with others. A social network illustrates the connections and flows that exist between individuals, groups, organizations, and other information or knowledge processing units (Computer Hope, 2021). 


\section{Social Networking Sites (SNS)}

The sites introduced or established to develop connections, interactions and conversations between the people via online medium are known as social networking sites. For instance, Facebook is the world's largest social networking site which helps to make people connected, share the contents and moments with each other, develop relationships, provide educational information and so on. Social networking sites are mainly utilized to build the contact and network of the people. Some of the popular social networking sites include; Facebook, YouTube, Twitter, Tik Tok, Snapchat and so on (Computer Hope, 2021).

\section{Methodology}

There are a diverse set of people in Nepal. Diverse set of people delivers a diverse set of opinions and feedback to a particular topic. Using a simple and random social media related questionnaire, a survey was conducted, in which people from different professions participated. The survey was conducted through the assistance of google form which contains a good set of questions related to social media/networking. Altogether 56 individuals responded to the questions and through that a different set of data were collected which provided the public concept regarding social media and its impacts.

Data was gathered through the questionnaire which was asked to respond by the respondents. The responses were unique and real time. Out of 56 copies of the questionnaire sent to the respondents, all the copies were retrieved. This represented a response rate of $100 \%$. These responses represent that social media is a very interesting and attentiongrabbing topic to be discussed on.

\section{Data Interpretation and Analysis}

The analysis is done through the survey conducted using the google form. The data of the survey along with the analysis is presented below;

\section{Question 1}

\section{What is your age?}

Answer: Around $70 \%$ of the respondents were between the age group of 20 and 25 , $25 \%$ were from the age group between 26 and 32 and 5\% from the age group between 33 and above. The involvement of the youth was high in this survey.

\section{Question 2}

\section{What is your profession?}

Answer: According to the survey, around $30 \%$ of the respondents belonged to the student profession. The respondents from the businessman and IT related profession were $20 \%$ each, teacher, gamer and singer were $4 \%$ each. Almost $16 \%$ respondents were from doctor, educational consultant, accountant, photographer, marketing manager, actor, singer, counsellor, bank, and nurse profession. Remaining 2\% were unemployed. The above data illustrates that the student professions were the most involved in the social media/ network, this may lead them to distraction on their studies. Similarly, IT professions and businessmen were also observed being engaged in the social network. Teachers were also mostly into social media platforms which may lead to inefficiency at their task as they might be found wasting their time on social media sites rather than teaching their students informatively and sincerely. It might impact positively to the jobless individual as it assists them to get valuable information and knowledge from social media and its platforms. 


\section{Question 3}

How often do you use social media?

\begin{tabular}{|l|l|}
\hline Responses & Percentage (\%) \\
\hline Never & 0 \\
\hline Sometimes & 23.2 \\
\hline Frequently & 48.2 \\
\hline Excessively & 28.6 \\
\hline
\end{tabular}

Table 1: Survey Question 3

\section{Question 4}

Do you believe that social media can play a vital role in the development of the nation?

\begin{tabular}{|l|l|}
\hline Responses & Percentage (\%) \\
\hline Yes & 71.4 \\
\hline No & 1.8 \\
\hline May be & 26.8 \\
\hline
\end{tabular}

Table 2: Survey Question 4

\section{Question 5}

Would you prefer the world with the presence or the absence of social media?

\begin{tabular}{|l|l|}
\hline Responses & Percentage (\%) \\
\hline Presence & 98.2 \\
\hline Absence & 1.8 \\
\hline
\end{tabular}

Table 3: Survey Question 5

\section{Analysis of Survey Response}

According to the surveyed data of question number 3,4 , and 5 , it can be analyzed that there is a huge number of publics using social media or networks. About $28 \%$ of respondents stated that they utilize social media excessively which is a great number. Around $71 \%$ of respondents believe that social media can play a vital role in the development of the country. The respondents certainly agree with the presence of social media as $98 \%$ of respondents from the survey voted for the presence of social media in the world. Through this data analytics we can guess the essentiality of social media in the present context.

\section{Question 6}

Which one is your most preferred social media platform?

\begin{tabular}{|l|l|}
\hline Responses & Percentage (\%) \\
\hline Facebook & 35.7 \\
\hline WhatsApp & 7.14 \\
\hline Instagram & 10.7 \\
\hline YouTube & 26.8 \\
\hline Twitter & 1.78 \\
\hline LinkedIn & 5.35 \\
\hline Tik Tok & 10.7 \\
\hline Snapchat & 1.78 \\
\hline
\end{tabular}

Table 4: Survey Question 6

\section{Analysis of Survey Response}

Considering all the profession's individual, the most preferred social media platform turned out to be Facebook. 35.7\% respondents preferred Facebook as their priority social media platforms followed by YouTube (26.8\%), Instagram (10.7\%), Tik Tok (10.7\%), WhatsApp (7.14\%), LinkedIn (5.35\%), Twitter (1.78\%), Snapchat (1.78\%).

\section{Question 7}

Would you give access to social media to your children? Give your opinion.

\begin{tabular}{|l|l|}
\hline Responses & Percentage (\%) \\
\hline Yes & 35.7 \\
\hline No & 32.1 \\
\hline May be & 32.1 \\
\hline
\end{tabular}

Table 5: Survey Question 7 


\section{Question 8}

Do you consider that social media has been creating negative impacts on the young generation?

\begin{tabular}{|l|l|}
\hline Responses & Percentage (\%) \\
\hline Yes & 21.4 \\
\hline No & 8.9 \\
\hline May be & 42.85 \\
\hline Neutral & 16.1 \\
\hline Unknown & 10.75 \\
\hline
\end{tabular}

Table 6: Survey Question 8

\section{Analysis of Survey Response}

According to the surveyed data of question number 7 and 8 , it can be observed that even though the majority of respondents believe that social media can spread negative impacts to the youth, still they give their kids access to the social media. There can be enormous reasons for that, it can be possible due to educational and communication purposes. As nowadays schools provide online classes so that the children require accessibility to such social media platforms in order to communicate and conduct their classes. This turns out to be the positive impact of social media.

\section{Question 9}

Which do you think is the major advantage of social media?

\begin{tabular}{|l|l|}
\hline Responses & $\begin{array}{l}\text { Percentage } \\
(\mathbf{\% )}\end{array}$ \\
\hline $\begin{array}{l}\text { Provides Communication } \\
\text { Services }\end{array}$ & 33.9 \\
\hline $\begin{array}{l}\text { Creates employment and other } \\
\text { opportunities }\end{array}$ & 19.6 \\
\hline Entertainment & 23.2 \\
\hline Provides Marketing Platforms & 14.3 \\
\hline Promotes Art and Creativity & 8.9 \\
\hline
\end{tabular}

Table 7: Survey Question 9

\section{Question 10}

Which do you think is the major disadvantage of social media?

\begin{tabular}{|l|l|}
\hline \multicolumn{1}{|c|}{ Responses } & \multicolumn{1}{|c|}{$\begin{array}{c}\text { Percentage } \\
\text { (\%) }\end{array}$} \\
\hline $\begin{array}{l}\text { Excessive use of social media } \\
\text { leads to the waste of time }\end{array}$ & 30.4 \\
\hline $\begin{array}{l}\text { Can harm the health of the } \\
\text { consumers }\end{array}$ & 8.9 \\
\hline $\begin{array}{l}\text { Possibility of Cyber Crime } \\
\text { and Hacking }\end{array}$ & 53.6 \\
\hline $\begin{array}{l}\text { Can ruin the relationships and } \\
\text { trusts }\end{array}$ & 5.35 \\
\hline $\begin{array}{l}\text { Making the interface addictive } \\
\text { to the people }\end{array}$ & 1.78 \\
\hline
\end{tabular}

Table 8: Survey Question 10

\section{Analysis of Survey Response}

There exists both the positive and negative side of social media. So, question number 9 and 10 represent the advantages and disadvantages of social media respectively. There are broad advantages of social media like; it provides communication services, creates employment and other opportunities, source of entertainment, provides marketing platforms, promotes art and creativity and so on. Among them around $34 \%$ of respondents found out that providing communication services to be the major advantage of social media. Along with that there are also few dark sides of social media like; excessive use may lead to waste of valuable time, can harm the health of the consumers, can import cybercrime and hacking, can ruin the relationships and trusts, can be addictive to the people and so on. Among them, around $54 \%$ of respondents found out the possibility of cybercrime and hacking as the major and serious disadvantage of social media. 


\section{Question 11}

What do you think is the major reason for joining social media?

\begin{tabular}{|l|l|}
\hline Responses & $\begin{array}{c}\text { Percentage } \\
\text { (\%) }\end{array}$ \\
\hline $\begin{array}{l}\text { Convey with the relatives, } \\
\text { friends, and family members }\end{array}$ & 37.5 \\
\hline Share the moments & 26.8 \\
\hline Educational purpose & 17.9 \\
\hline In order to pass the time & 8.9 \\
\hline $\begin{array}{l}\text { To find and contact with the } \\
\text { old and new people }\end{array}$ & 8.9 \\
\hline
\end{tabular}

Table 9: Survey Question 11

\section{Analysis of Survey Response}

There are quite a lot of reasons for joining social media. Some of the reasons include; in order to communicate between the relatives, peers and family members, to share the precious moments, for educational purposes, to pass the time, to find out and contact with the old and new people and many more. From the survey, we can find that $37.5 \%$ of respondents considered that their reasons for joining social media is for communication purposes. They treat social media as a platform to converse with relatives, friends and family members.

\section{Question 12}

Rate the importance of social media. ( 1 is considered less important and 5 is highly important)

\begin{tabular}{|l|l|}
\hline Responses & Percentage (\%) \\
\hline 1 & 1.8 \\
\hline 2 & 0 \\
\hline 3 & 12.5 \\
\hline 4 & 55.4 \\
\hline 5 & 30.4 \\
\hline
\end{tabular}

Table 10: Survey Question 12

\section{Analysis of Survey Response}

In the scale measurement of social media importance from 1 (i.e., less important)-5 (i.e., highly important), $55.4 \%$ of respondents have given 4 ratings which indicates that there is an immense importance of social media in today's world.

\section{Question 13}

\section{Any suggestions?}

Some of the valuable comments and suggestions that are provided by the respondents.

\section{Summary of Findings}

The findings showed that;

$\checkmark$ On the basis of the survey, it can be assumed that a large proportion of the population in the country utilizes social media and its platforms. Facebook is the social media platform that is preferred by the majority of the people, followed by YouTube, Instagram, Tik Tok, WhatsApp, LinkedIn, Twitter, and Snapchat.

$\checkmark$ The reasons why people of Nepal join social networks include meet new people, find old friends, chat the day away, join interest group, create photo album and share photos, get advice, help, belong.

$\checkmark$ Approximately around 25\% of the public agreed that social media also has a negative impact on youth.

$\checkmark$ Although people believe that social media also exhibits negative impacts, they also give access to their children.

$\checkmark$ Because of the higher number of crimes committed on social networks and the amount of time spent on social networking activities, as well as the failure to develop a balance between 
social media and education, business and at the workplace, social networking is considered to create a negative impact. The positive effects of such social media includes: it enables open communication, delivers opportunity to widen business contact, makes it simpler and easier to stay in touch with family, peers and relatives.

After observing and analyzing, it can be concluded that the majority of the people believe that social media is an essentiality in today's world and it is very hard to imagine the world in the absence of social media and its platforms.

\section{Conclusion}

Despite social networking being an occurrence which has existed since the beginning of civilization, social networking sites are a recent trend. In less than five years, these sites have evolved from a minor online campaign to a wonder where tens of millions of internet users are attached. The advent of a new social phenomenon has sparked debate in both industry and academics. Taking the findings of this report's investigation as a basis, the following conclusions have been reached:

Social networking may appear to have certain negative repercussions in society, yet it is still more advantageous than the negativity devoted to it.

Banning access to social networking sites, like any other social problem or threat to individuals in society, is not the ideal solution. Young internet users are frequently curious and smart enough to discover new procedures and techniques of accessing social networking sites.

$\checkmark$ According to my interpretation of my investigation, social networking sites may have a substantial influence on the social behavior of youngsters. There have been observed both good and negative consequences documented of it. Positive effects of these sites include flourishment of togetherness among peers and family as well as the ability to communicate openly. Communication, among other things, including aiding others and so on. On the other side, bullying is one of the negative outcomes that have been determined, and various stages of addiction.

$\checkmark$ Finally, the advent of social networking sites is essential to the advancements of the social and economic repercussions of new technologies. As several networking sites observers have remarked, the constant growth of these sites showers with the new opportunities and concerns. As a result, this study has sought to deliver some modest contributions about the several social trends and their consequences inherent in the current rise of social networking sites.

\section{Recommendations}

In accordance with the examination of social media's influence on society. Following points are recommended by me;

$\checkmark$ The guardian of the country, i.e., the government, should encourage both the young and the old by making internet access more affordable, which will contribute in creating golden chances and opportunity to access social networks, which encourages togetherness and affection among individuals particularly the inhabitants of the nation.

$\checkmark$ The government should discover a procedure to secure social networking sites in order to minimize fraud activities of hackers, as this is the most significant 
negative consequence of networking sites in our surroundings.

As a source of knowledge, parents should introduce their offspring to social networking in order to make them more effective in understanding what is going on across the globe.

Moreover, the pillar of the nation, i.e. youth, should attempt not to waste their valuable time on social networking sites in order to not harm their academic performance, instead they should make reasonable utilization of the good aspects of social networking.

Furthermore, awareness elevating and educational programs emphasizing safe and secure use of social networking sites are must. It is essential that individuals understand and learn how to handle their online data. Such educational activities and events should include the guardian's participation as well.

\section{References}

Computer Hope. (2021). What is a Social Network? Retrieved from Computer Hope: https://www.computerhope.com/jargon/s/ socinetw.htm

DataReportal . (2021). Digital 2021 July Global Statshot Report. DataReportal - Global Digital Insights. Retrieved from DataReportal : https://datareportal.com/reports/digital2021-july-global-statshot

DataReportal. (2021). Global Social Media Stats. DataReportal. Global Digital Insights. Retrieved from DataReportal: https://datareportal.com/social-mediausers\#: :text=Facebook remains the world's most,platforms are owned by Facebook.\&text=QQ (腾讯QQ) has 591 million monthly active users.
Investopedia. (2021). Social Media Definition. Retrieved from Investopedia: https://www. investopedia.com/terms/s/social-media.asp

Lifespan. (2020). Pros and Cons of Social Media. Retrieved from Lifespan: https://www. lifespan.org/lifespan-living/social-mediagood-bad-and-ugly\#: :text=The more time spent on,Social Media is addicting.\&text $=$ But that's not all\%2C social,Fear of Missing Out.

Questex LLC. (2021). The top 10 pharma companies in social media. Retrieved from FiercePharma: https://www.fiercepharma. com/special-report/top-10-pharmacompanies-social-media- 0

Smart Insights. (2021). Global social media statistics research summary 2022. Retrieved from Smart Insights: https://www. smartinsights.com/social-media-marketing/ social-media-strategy/new-global-socialmedia-research/\#: :text=More than half of the, access to a mobile phone

Techopedia. (2021). What is the Internet? Definition from Techopedia. Retrieved from Techopedia: https:/www.techopedia.com/ definition/2419/internet

L. Hjorth, \& S. Hinton (2019), Understanding Social Media. SAGE. Retrieved December 5, 2021, from https://books.google.com. $\mathrm{np} /$ books?hl=en\&lr=\&id=ZL6rDwAAQ BAJ\&o $i=$ fnd \&pg $=$ PP $1 \& d q=$ what + is + so cial + media\&ots $=Q 8 w U v j b U b r \& s i g=K R$ IJNP1zL1Ep-NEvFcheol4AoTM\&redir es $\mathrm{c}=\mathrm{y} \# \mathrm{v}=$ one page $\& \mathrm{q}=$ what $\% 20$ is $\% 20$ social $\% 20$ media $\& f=$ false

Utopia Educators. (2021). Psychological Effects of Social Media on Teenagers. Retrieved 2021, from Utopia Educators: https:// utopiaeducators.com/psychological-effectsof-social-media/ 


\section{Annex}

a) Survey Questionnaires

\section{Question 1}

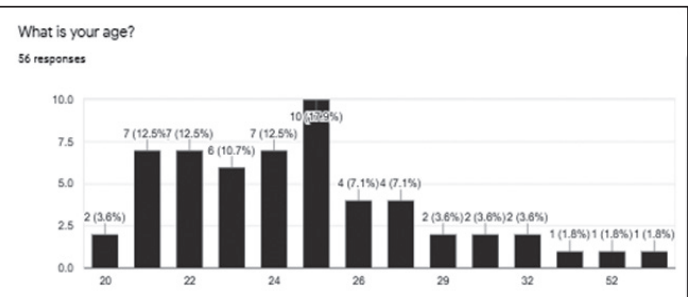

Figure 4: Survey Question 1

\section{Question 2}

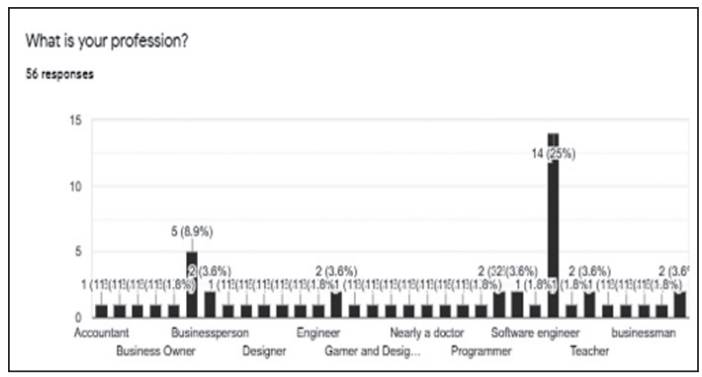

Figure 5: Survey Question 2

\section{Question 3}

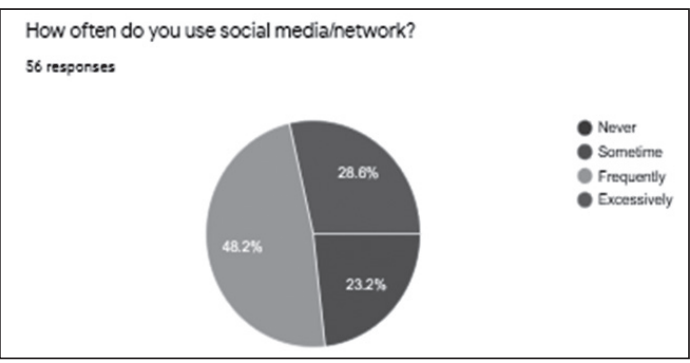

Figure 6: Survey Question 3

\section{Question 4}

Do you believe that social media can play vital role in the development of the nation? 56 responses

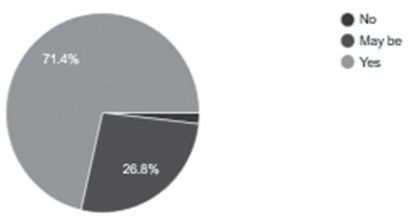

Figure 7: Survey Question 4

\section{Question 5}

Would you prefer the world with the presence or absence of social media/network? 56 responses

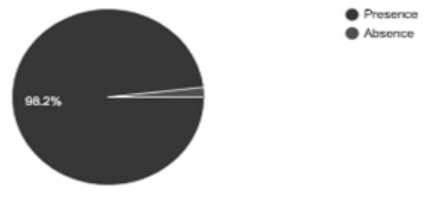

Figure 8: Survey Question 5

\section{Question 6}

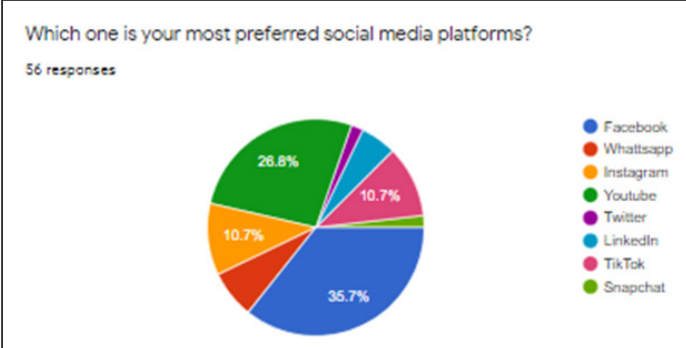

Figure 9: Survey Question 6

\section{Question 7}

Do you give access to social media to your children? Give your opinion. 56 responses

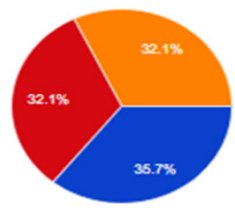

- Yes

May be

Figure 10: Survey Question 7

Do you consider that social media has been creating negative impacts to the young generation?

56 responses

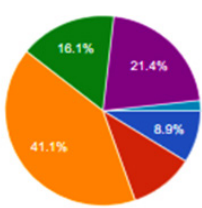

No

\section{Question 8}

Figure 11: Survey Question 8 


\section{Question 9}

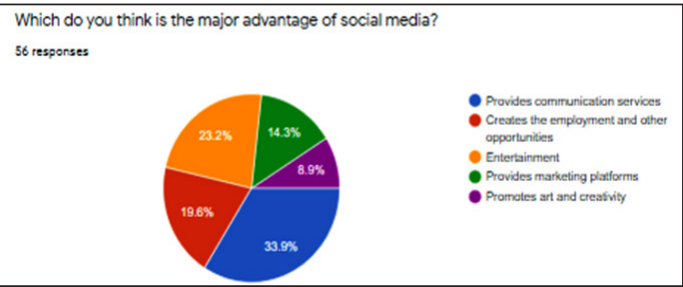

Figure 12: Survey Question 9

\section{Question 10}

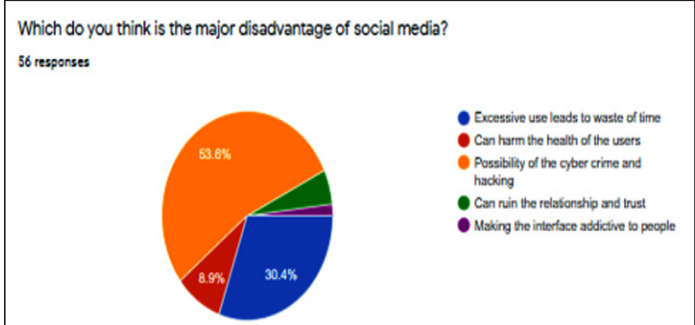

Figure 13: Survey Question 10

\section{Question 11}

What do you think is the major reasons for joining social media?

56 resporses

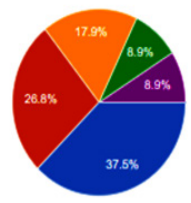

- Convey with the rolatives, fiends and family menbers

- Share the moments

- Educational purpose

- In order to pass the fime

- Find and contact with the old and nee

pecople

Figure 14: Survey Question 11

\section{Question 12}

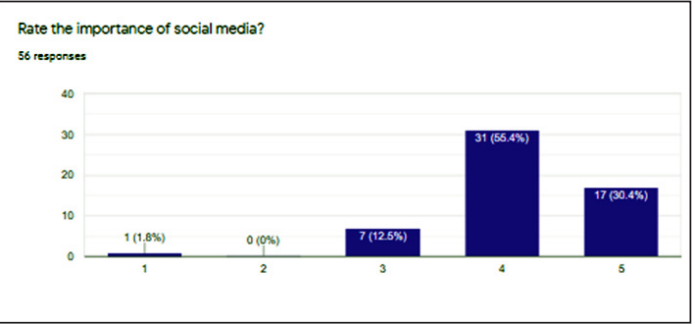

Figure 15: Survey Question 12

\section{Question 13}

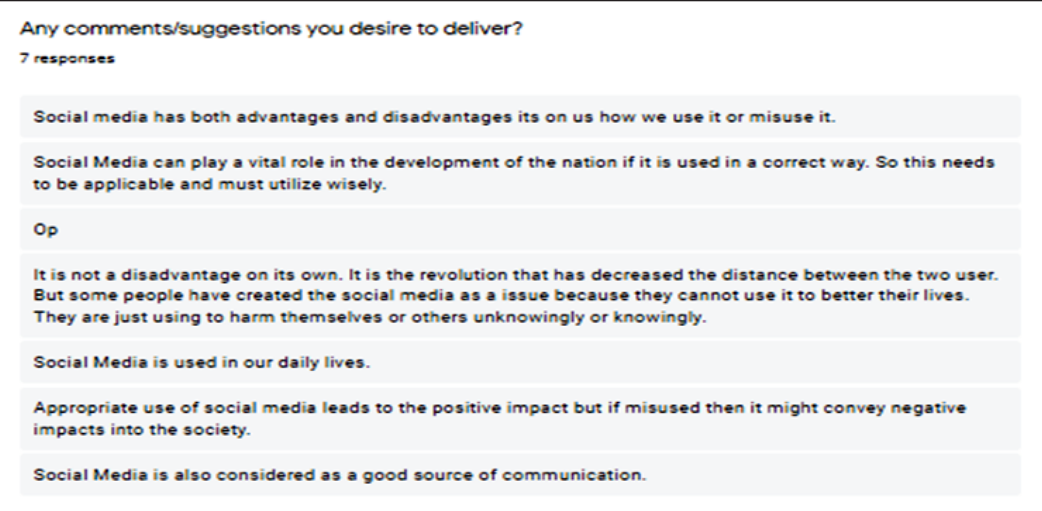

Figure 16: Survey Question 13 